\title{
O que é lixo afinal? Como pensam mulheres residentes na periferia de um grande centro urbano
}

\author{
What is garbage, anyway? The opinions \\ of women from an outlying neighborhood \\ in a large Brazilian city
}

Rita de Cássia Franco Rêgo 1

Maurício L. Barreto 1

Cristina Larrea Killinger 1,2

\footnotetext{
1 Instituto de Saúde Coletiva Universidade Federal da Bahia. Rua Padre Feijó 29, Salvador, $B A$

40110-170, Brasil. ritarego@lognet.com.br 2 Departament

d'Antropologis Cultural i Història d'Amèrica $i$ Àfrica, Divisio de Ciencies

Humanes $i$ Socials, Universitat de Barcelona. Cúpules Torre-B, Baldiri Reixac s/n, Barcelona 08028, Espanya.
}

\begin{abstract}
Domestic solid waste is cause for current environmental concern in large cities around the world. Little is known about the human health consequences of solid waste disposal in openair dumps. In addition, there are few studies on people's health practices in relation to solid waste. As the initial step in epidemiological research on the relationship between solid waste and diarrhea, this study describes women's perception of the definition of garbage and the popular understanding of the relationships between garbage and disease, and between garbage and the environment. The study used a qualitative approach in a slum neighborhood in Salvador, Bahia. A total of 13 women were interviewed using a semi-structured questionnaire in 1999. The FileMaker "diaricamp" application was used for data analysis. Interviewees defined garbage as anything useless and considered it a problem whenever it accumulated in the surroundings producing a bad smell or visual pollution, attracted animals, caused disease in children or adults, or was shifted from the individual to the collective/institutional sphere of action to solve the problem.
\end{abstract}

Key words Garbage; Solid Waste; Environment; Sanitation

Resumo O lixo urbano constitui-se hoje uma preocupação ambiental nos grandes centros urbanos e ainda pouco se conhece sobre os efeitos à saúde causados pela disposição do mesmo a céu aberto, coleta inadequada e as práticas sanitárias da população em relação a estes resíduos. Como etapa inicial de um estudo epidemiológico que buscou a relação entre exposição ao lixo e diarréia em crianças, desenvolveu-se este estudo com o objetivo de conhecer como mulheres, residentes na periferia de um grande centro urbano, definem lixo, bem como as mesmas percebem a relação entre lixo e doença e entre lixo e outros aspectos ambientais. Em 1999, realizaram-se entrevistas com treze mulheres, em um bairro da periferia de Salvador, utilizando-se um roteiro semi-estruturado. Para a análise das entrevistas utilizou-se o aplicativo "diaricamp" do programa FileMaker. As entrevistadas definem o lixo como tudo que não serve para ser utilizado e o consideram como um problema quando este se encontra acumulado no ambiente, sendo capaz de provocar incômodos como mau cheiro ou poluição visual;quando serve como foco da presença de animais; provoca doenças em crianças e adultos, ou quando o poder para a solução do problema se desloca da esfera individual para o âmbito coletivo ou institucional.

Palavras-chave Lixo; Resíduos Sólidos; Meio Ambiente; Saneamento 


\section{Introdução}

Os resíduos sólidos urbanos (RSU), mais conhecidos como lixo, constituem uma preocupação ambiental mundial, especialmente em grandes centros urbanos de países subdesenvolvidos. Pouco se conhece sobre as repercussões da disposição desses resíduos a céu aberto na saúde humana e das práticas sanitárias da população em relação a eles. A geração de RSU, proporcional ao crescimento populacional, suscita uma maior demanda por serviços de coleta pública e esses resíduos, se não coletados e tratados adequadamente, provocam efeitos diretos e indiretos na saúde, além da degradação ambiental.

A preocupação mundial em relação aos problemas ligados aos RSU consta no capítulo 21 do documento final produzido na Conferência da Organização das Nações Unidas (ONU) sobre Meio Ambiente e Desenvolvimento (CNUMAD), a Eco-92. Este documento propõe como um dos principais compromissos da humanidade para as futuras gerações o Desenvolvimento Sustentável, que deverá conciliar justiça social, eficiência econômica e equilíbrio ambiental (UN, 1999).

As diretrizes da Agenda 21 brasileira seguem as recomendações da CNUMAD e indica como estratégias para o gerenciamento adequado de RSU: a minimização da produção de resíduos; a maximização de práticas de reutilização e reciclagem ambientalmente corretas; a promoção de sistemas de tratamento e disposição de resíduos compatíveis com a preservação ambiental; a extensão de cobertura dos serviços de coleta e destino final (MMA, 1999).

$\mathrm{O}$ aumento na geração de RSU é um problema atual e crescente em diversos países da América Latina e Caribe (ALC), particularmente mais grave em países com maiores demandas e menor oferta de serviços de limpeza pública (Acurio et al., 1997). Não se sabe ao certo a quantidade de RSU produzida que não é coletada, estimando-se que não são recolhidos $30 \%$ a $50 \%$ dos resíduos gerados nas cidades dos países em desenvolvimento (OPS, 1993). Estimativas obtidas de documentos e informações de experts do setor de RSU da região da América Latina e Caribe apontam uma taxa de geração per capita diária de 0,3 a 0,8kg/habitantes/dia de resíduos sólidos domiciliares (RSD) e de 0,5 a 1,2kg/habitantes/dia de Resíduos Sólidos Municipais (RSM - provenientes da geração residencial, comercial, institucional e de pequena indústria e artesanato), sendo a média regional deste último de $0,92 \mathrm{~kg} /$ habitantes/dia (Acurio et al., 1997).
Na região da América Latina e Caribe, 70\% dos RSM são gerados nos domicílios e como são resultantes da atividade econômica, os países mais pobres, além de gerarem menos resíduos, apresentam menor proporção de componentes recicláveis (Acurio et al., 1997).

Segundo os dados da Pesquisa Nacional de Amostra de Domicílios (PNAD), realizada no Brasil em 1996, 79,9\% dos domicílios particulares permanentes tinham o lixo coletado (IBGE, 2000). Entretanto, o acesso à coleta no Brasil apresenta características de desigualdades, conforme a região. Em 1996, o Nordeste apresentava a menor taxa de lixo coletado $(59,7 \%)$ e a região Sudeste a maior, com 90,1\% (IBGE, 2000). Salvador apresentava, em 1999, uma população beneficiada por coleta de lixo de 94,1\% (DATASUS, 2000) e coletava $1,04 \mathrm{~kg} /$ habitante/dia de RSD (LIMPURB, 2000). Porém, estudo realizado em Salvador identificou ausência de coleta porta a porta em $44,0 \%$ dos domicílios, levando parte da população, particularmente aquela residente na periferia urbana, a depositar os resíduos domiciliares em canais, encostas e pontos de lixo (Barreto et al., 1999).

Vários estudos demonstram uma associação positiva entre ausência de saneamento e agravos à saúde (Esrey et al., 1991). Heller (1997), em revisão de 256 estudos sobre saneamento e saúde, identificou que $305(81,7 \%)$ relacionavam-se a esgoto e água, apenas $4(1,1 \%)$ referiam-se a lixo.

Alguns estudos realizados no Brasil têm apontado para uma possível associação entre manejo inadequado de RSU e o aumento de eventos mórbidos, notadamente diarréia e parasitoses intestinais, em crianças (Catapreta \& Heller, 1999; Heller, 1995; Moraes, 1997; Rêgo, 1996). Contudo, ainda são escassos os estudos que relacionam a saúde infantil com a presença de RSU no ambiente, permanecendo ainda pouco evidentes os mecanismos que envolvem esta relação (Heller, 1995).

Os processos de produção, disposição e coleta de RSU que ocorrem no interior das comunidades não estão dissociados de questões estruturais mais gerais que se dão na sociedade, geradoras de desigualdade quanto às condições de sobrevivência. Assim, a abordagem de aspectos qualitativos sobre a importância atribuída aos RSU, dispersos no ambiente, na saúde de populações periféricas, bem como dos hábitos dessas populações em relação aos RSU, podem constituir-se em elementos esclarecedores sobre o modo como os riscos ocorrem, podendo vir a assumir importância científica como delineador das políticas ambientais e na garantia da preservação das gerações futuras. 
A análise das conseqüências da exposição direta ou indireta aos RSU é considerada uma tarefa complexa, exigindo a participação integrada de profissionais das mais diversas formações disciplinares unidos por interesses comuns (Sisinno \& Oliveira, 2000). Neste contexto, os desenhos de investigação na área ambiental associando o potencial de maior generalização do método quantitativo, com o de maior aprofundamento do método qualitativo, podem possibilitar importantes contribuições para o estudo da relação entre meio ambiente e saúde (Huttly et al., 1998; Jenkins \& Howard, 1992).

O presente estudo, desenvolvido no contexto de uma pesquisa epidemiológica que procura uma possível relação entre a presença de RSU no ambiente e diarréia em crianças, é uma primeira aproximação, de caráter qualitativo, que busca identificar como os moradores de uma periferia urbana conceituam "lixo" e compreendem a relação entre exposição a este fator ambiental e a saúde.

\section{Metodologia}

Trata-se de um estudo qualitativo, que utiliza a técnica de avaliação etnográfica rápida (Rapid Ethnographic Methodology - REM), já aplicada em pesquisas na área de saúde (Bentley et al., 1988). O presente estudo foi realizado no bairro de Nova Constituinte, situado na periferia da cidade de Salvador, que apresenta problemas graves de infra-estrutura urbana (Larrea \& Barreto, 1999). A população estimada desse bairro, segundo a última PNAD realizada pelo IBGE em 1996, era de 9.748 habitantes com uma renda familiar média de 1,4 salário mínimo (Larrea \& Barreto, 1999).

Foram selecionadas treze famílias mediante contatos existentes durante uma pesquisa etnográfica desenvolvida previamente nos anos de 1997 e 1998, quando uma das autoras (C. L. K.) permaneceu por nove meses na área (Larrea \& Barreto, 1999). Os critérios mínimos para a seleção das famílias foram: residir na localidade e possuir ao menos uma criança com idade inferior a três anos. Considerou-se também a heterogeneidade das famílias em relação à composição familiar, à educação, à atividade econômica e à religião.

As entrevistas do presente estudo foram realizadas em outubro de 1999, na própria casa das informantes, por dois dos autores (C. L. K. e R. C. F. R.), utilizando-se como instrumento um roteiro semi-estruturado. Foram realizadas treze entrevistas gravadas em fitas, com a duração média de quatro horas cada. Todos os in- formantes eram mulheres, moradoras do bairro, na faixa etária entre 18 a 45 anos. As gravações foram transcritas e revisadas em novembro de 1999. Para preservar a identidade das informantes, todos os nomes utilizados neste texto são fictícios.

Durante a sistematização das entrevistas, realizou-se inicialmente a leitura livre das transcrições, anotando-se as primeiras interpretações em relação ao tema estudado. Em seguida, procedeu-se à categorização interna das mesmas, utilizando-se o roteiro de pesquisa como um guia de sistematização dos dados. Posteriormente, todas as entrevistas foram comparadas com o objetivo de verificar aspectos recorrentes, convergentes e divergentes, além das exceções, buscando-se sempre a relação com a categoria central deste estudo: a definição de lixo e a sua relação com a saúde.

Utilizou-se o aplicativo "Diari Camp", do programa FileMaker Pro 4.1 (FileMaker Incorporation, 1994), para a sistematização em três níveis das entrevistas transcritas. No primeiro nível, realizou-se a classificação dos temas principais da pesquisa e das palavras-chave; no segundo, efetuou-se a categorização das palavras conceitos e das palavras relacionadas; e no terceiro, anotaram-se as categorias "etic" (ponto de vista do pesquisador) e "emic" (ponto de vista do informante).

\section{Resultados}

Os resultados obtidos foram organizados de acordo com as seguintes categorias: o que é lixo para o sujeito; processo de produção, destino, coleta e reaproveitamento do lixo; por que o lixo é um problema; lixo e doenças; lixo e outros fatores ambientais; responsabilidade pública, individual e coletiva em relação ao lixo.

\section{O que é lixo para o sujeito}

O lixo foi definido pelas entrevistadas em função de sua utilidade, da sua disposição final e da relação do mesmo com a saúde (se causa doenças ou não). A definição mais usada pelas mulheres foi de que "lixo é tudo aquilo que não serve para ser utilizado”. Alguns produtos classificados como lixo eram também considerados aproveitáveis ou recicláveis pelas entrevistadas. Notou-se uma distinção de conceitos entre o que é considerado "velho" e o que é lixo, ou “o que não presta”. Assim, aquilo que é velho, mas que pode ser útil, não é classificado como lixo, como por exemplo mobiliário. Segundo as mulheres, o lixo é o que não serve pa- 
ra ser utilizado e, portanto, aquilo que não pode constituir-se num produto de uso, venda ou troca. Elas demonstram uma escala de valorização dos produtos, considerando que aquilo que é lixo para algumas pessoas pode ser considerado de grande utilidade para outras.

Vários produtos foram considerados lixo: restos de alimentos, cascas de frutas e verduras, papel usado, sujeira da varrição da casa, roupas velhas, papel higiênico usado, papelão, fezes humanas e de animais, mato, podas de árvores, latas e vidros usados, pilhas de rádio descarregadas, pneus de borracha estragados, plásticos usados, eletrodomésticos velhos, panelas de alumínio velhas, ferro velho, restos de construções. Dentre estes, os únicos considerados, por todas as entrevistadas, como não reaproveitáveis ou recicláveis foram: sujeira de varrição, mato, fezes humanas e de animais, papel higiênico usado e pilhas de rádio descarregadas.

Salienta-se que as fezes foram consideradas lixo, e isto, em parte, relaciona-se à ausência de sanitário nos domicílios, levando as famílias a acondicionarem as fezes em jornais e sacos plásticos ("balão"), depositando-as em riachos, canais que servem como esgoto, valas ou pontos de lixo doméstico. Em geral, as fezes eram enterradas no quintal da casa ou colocadas nas proximidades da mesma, em sacos separados do lixo produzido diariamente, favorecendo a contaminação peridomiciliar. A disposição final era feita no mesmo local do lixo doméstico. As fezes das crianças menores eram freqüentemente jogadas no quintal, às vezes sem acondicionamento.

\section{Processo de produção, destino, coleta e reaproveitamento do lixo}

Para as entrevistadas, a maior parte do lixo produzido diariamente pela família é orgânico, constituído por restos de alimentos, cascas de frutas e de verduras. A atividade de enterrar ou jogar o lixo e as fezes até o ponto para ser coletado era realizada diariamente ou em dias alternados. Esta tarefa era freqüentemente realizada por mulheres ou crianças acima de oito anos de idade, que, às vezes, ganhavam dinheiro da vizinhança para a execução da mesma.

As entrevistadas relataram o reaproveitamento dos produtos antes destes serem jogados ao lixo. Assim, cascas de verduras viravam sopas, restos de frutas tornavam-se adubo para as plantas, sobras de alimentos serviam de alimentação para os animais. Algumas das entrevistadas já exerceram, ou ainda exercem, atividades que utilizam o lixo (latas, vidros e pape- lões) como fonte de renda. As relações de doações e trocas são comuns na comunidade, com relatos de pessoas que afirmam que sem isso não haveria móveis em suas casas.

As relações de troca são por vezes evitadas para alguns objetos de uso pessoal, como roupas, devido ao receio, apontado por algumas entrevistadas, de que aquele objeto possa ser utilizado em rituais mágico-religiosos, no sentido de maldade ou feitiço, realizado por pessoas que desejam mal ao proprietário do objeto.

As mulheres demonstraram no seu discurso o conhecimento da classificação de periculosidade dos produtos. Pilhas de rádio descarregadas, restos de desinfetantes e de medicamentos eram percebidos como perigosos; porém, eram descartados no lixo comum. Notouse, entretanto, um certo cuidado para que as crianças não mantivessem contato com esses elementos.

\section{Por que o lixo é um problema}

Segundo as mulheres, o lixo é em um problema na medida em que, acumulado no ambiente, é capaz de produzir odor desagradável, contribuir com mecanismos que provocam desastres como enchentes e alagamentos, servir como foco de atração de animais (gatos, cães, ratos, baratas, cobras, insetos) e provocar doenças em crianças e adultos.

Outras vertentes, explicitadas nas entrevistas, relacionam-se ao poder para a solução dos problemas ligados ao lixo, que deixam de ser de âmbito individual tornando-se uma questão coletiva e institucional, ou ainda quando a solução destes problemas acarretam custos para o já tão escasso orçamento doméstico. Algumas pessoas informaram que a ausência de coleta em locais próximos aos domicílios obriga os moradores a colocarem o lixo em pontos cada vez mais distantes. Em conseqüência deste fato, os moradores pagam pessoas da comunidade para transportarem o lixo domiciliar até as caixas coletoras em pontos estabelecidos pelo órgão de limpeza pública, causando ônus financeiro ao já escasso orçamento doméstico, conforme relato abaixo.

"Porque, vamos supor, se, por exemplo, aqui tivesse uma caixa coletora seria mais fácil pra gente, a gente só era chegar ali e colocar, (...). (...) eu tenho que trabalhar fora pra poder eu pagar pra puder a pessoa botar lá, e se tivesse uma caixa coletora aqui não precisa fazer isso, já era um pão a mais que era pra meus filhos, era um leite, um açúcar" (Érika).

Os pontos de depósito de lixo provocam incômodos como odor desagradável e problemas 
de saúde para os residentes em suas imediações. Relatou uma mulher, que morava a quase 15 metros de um desses pontos, que as suas crianças apresentavam problemas respiratórios decorrentes do odor desagradável provocado pelos resíduos e das queimadas realizadas no local.

"Era horrivel, os pessoal jogava animal mortos aí, a carniça batia toda aqui em casa, porque o vento, o vento, (...) então quando batia o vento, à tarde mesmo era horrível, e os pessoal queimava lixo aí durante o dia, não deixava pra queimar a noite, não tinha aquela consideração, aquela consciência de saber que ia incomodar, aí tocava fogo. Era horrível, eu tinha que ficar com as portas fechadas, a janela fechada, os meninos não podia ficar do lado de fora" (Camélia).

\section{Lixo e doenças}

De acordo com as entrevistadas, o lixo parece ser um problema que pode atingir pessoas de ambos os sexos e diferentes faixas etárias, sobretudo as crianças. Vários mecanismos foram apontados associando a relação entre o lixo e doenças. As principais patologias, sinais ou sintomas referidos pelas entrevistadas como decorrentes do contato com o lixo foram: verminoses, infecção intestinal (diarréia), gripe, leptospirose, dengue, meningite, dor de cabeça, dor de dente, febre, alergia e náusea.

Uma mãe descreveu como sua filha pequena adquiriu infecção intestinal em contato com o lixo ou pela transmissão hídrica.

"É, é porque aquela dali não güenta ver nada, tudo ela bota na boca, qualquer coisa que larga ali à toa, às vezes, ela vem com um canudo não sei de que é, um negócio de picolé, um pau de picolé, vem mastigando, negócio de pirulito, aí é ruim que tem gente que larga o lixo à toa lá na rua ela vai lá e pega, saco de geladinho vai e pega, pega e bota na boca, e isso ai ó ela pegou infecção intestinal. (...) Eu acho que foi, ou não foi o lixo, ou foi a água, (...) que ai dessas coisa que dão infecção (...). Ela tem, vai fazer dois anos, tem um ano e onze meses" (Nazú).

Outra mãe associa a parasitose intestinal de sua filha ao contato com o lixo.

"Acho que a verminose é problema de lixo também. Ela pequenininha (apontou a criança), ficou com problema de verminose, porque ela estava começando a se arrastar e eles iam pra rua andar lá fora de sandália e quando chegava aqui não tirava a sandália. Elas ia pro chão, botava a mão na boca e pegou verminose, então pegou de lixo, porque lixo é sujeira, né?" (Agda).
Freqüentemente eram citadas doenças transmitidas por vetores como ratos, baratas e moscas. Os roedores eram apontados em várias entrevistas e alguns casos graves de doenças na vizinhança foram relatados.

“(...) por exemplo, uma mosca vai senta lá naquele lixo, a mosca que senta lá, ela vem até aqui, pousa na comida, o rato mesmo, vamos supor, eles estão aqui, eles vão pra lá daqui a pouco, daqui a pouco eles vão pra lá, tem mijo de rato, eles pisam, vai fazer doença quando ele vê prejudica. Como eu conheço mesmo um rapaz que tá na UTI de mijo de rato" (Érika).

Algumas entrevistadas apontam mecanismos de associação entre a transmissão indireta por meio de cães com possíveis doenças provocadas pelo lixo. Segundo elas, a transmissão pode ocorrer pelas fezes desses animais, das patas, da saliva e dos pêlos, e as doenças afetam especialmente as crianças que mais freqüentemente brincam com estes animais. As pessoas que possuem animais domésticos costumam deixá-los em casa ou no quintal, sem restrições quanto ao contato das crianças com esses animais.

Uma das entrevistadas narrou que o mau cheiro decorrente do acúmulo de lixo é capaz de provocar mal estar, perda de apetite, cefaléia, náuseas, vômitos, sintomas que, segundo ela, se agravam em gestantes. Abaixo, um relato de experiência própria, sinaliza os efeitos provocados pelo mau cheiro.

"A mulher quando tá de gestante tudo incomoda (...). O mau cheiro de lixo assim (...) ainda mais quando ela tá com o estômago vazio, além de fazer mal a ela, faz mal à criança também (...). Eu não sei explicar se faz mal formação, mas que faz mal faz, a criança sei lá, rejeita aquilo que quer comer e fica, a criança se endurece na barriga (...). E também faz mal à criança, prejudica a criança, desenvolvimento da criança é dentro da gente, tudo isso provoca doença" (Camélia).

A própria relação entre os componentes do ambiente e a possível contaminação de plantas, quando em contato com água contaminada, próxima aos locais de disposição do lixo, são alguns dos mecanismos apontados nas entrevistas como prejuízos que o lixo pode acarretar ao ambiente. Relato de entrevistada atribui a possibilidade de as plantas próximas a locais onde o lixo é depositado adoecerem, como é exposto abaixo:

"Como aqui, por exemplo, vamos supor: eu planto um aipim, uma batata ali perto daquele lixo, aquele aipim, aquela batata eu não acho que vai sair uma alimentação boa pra meus filhos, porque se tá perto do lixo? (...) lixo ali a 
água que cai vai filtrar na terra. Então foi por isso que eu também deixei de fazer plantação ai no quintal" (Érika).

\section{Lixo e outros fatores ambientais}

Alguns problemas provocados pelo lixo acumulado no meio ambiente foram relatados nas entrevistas, quais sejam: contaminação da água de consumo, deslizamento de encostas, alagamentos, enchentes, poluição atmosférica e degradação do solo. Relatos apontam a presença de lixões clandestinos espalhados pela cidade em locais próximos a lagoas onde são jogados até mesmo resíduos industriais. São locais sujeitos à degradação ambiental, que se tornam focos de doenças para as populações vizinhas que, por sua vez, freqüentemente, consomem produtos jogados nesses locais.

Os relatos apontam que o somatório dos problemas de drenagem, acúmulo de lixo, elevado índice pluviométrico e topografia da cidade expõem as populações que residem em áreas de encostas e baixadas às mais variadas situações de deslizamento de terra e enchentes provocando, por vezes, vítimas fatais nessas localidades. Quando questionada sobre a existência de uma possível relação entre lixo e drenagem, uma moradora relata, de forma clara, a interface de fatores ambientais:

“(...) Eu não sei explicar, mas eu acho que tem a ver por causa do lixo sim, sabe por quê? (...) onde a água tá correndo, tava cheio de saco, cheio de plástico parecendo que tava... ele, por causa, ó cada pedá de terra que caía lá na frente também, tinha meio mundo de lixo, ia junto, sabe?"

“(...) A água vem muito forte, entupida $e$ quebra tudo e esse rego ai ficou um tempo assim até meio entupido, porque tinha muito lixo, sabe? (...) Aí, a água, em vez de descer pra como ela sempre fazia, não, ela começou a espalhar e o terreno ficou encharcado sabe? Aí qualquer chuva assim que dá o terreno, é ali alaga tudo ali. Tem tempo que assim da água passar na perna da gente, uma semana a gente sem poder sair de casa (...). (...) a casa de laje dali da frente já ia caindo, se a chuva não parasse já ia caindo, os postes de luz tudo pro meio da rua, aquele poste grande correu, ficou, quase caiu em cima da casa da mulher" (Nazú).

No relato acima, a moradora explica como o lixo acumulado entope os canais de drenagem causando alagamentos. Durante as chuvas, o lixo e dejetos das casas acima da encosta deságuam para a baixada provocando deslizamentos de terra, inundações, infiltrações das casas e acidentes fatais. Tais eventos são co- muns em Salvador durante o período de chuvas e considerados uma fatalidade pelas autoridades que, corriqueiramente, não atentam para a relação entre os fatores referidos acima (falta de coleta de lixo somada à falta de drenagem e chuvas freqüentes levando aos deslizamentos e enchentes).

\section{Responsabilidade pública, individual e coletiva em relação ao lixo}

Os relatos apontam para um consenso de que o lixo é um problema de responsabilidade dos poderes públicos, ainda que seja também de âmbito individual e da comunidade (da vizinhança). A responsabilidade assume uma dimensão individual na medida em que cada um é responsável por jogar o seu próprio lixo em local adequado, e aqueles que não o fazem, geram problemas para a comunidade.

Apesar de reconhecerem a responsabilidade individual em relação ao processo de produção e de disposição do lixo, quando observados, eles demonstram nem sempre cumprir as responsabilidades atribuídas a si próprios. Quase sempre culpam os "outros” de jogarem o lixo em locais inadequados. Responsabilizam a vizinhança, chamando-os de "mal educados"; os poderes públicos pelos equipamentos inadequados e insuficientes, colocados em locais impróprios; e a falta de coleta regular. Embora várias entrevistas apontassem a responsabilidade do poder público quanto à coleta do lixo, nenhuma delas identificou o acesso à coleta como um direito.

As entrevistadas reconhecem que o órgão de limpeza pública realiza a coleta, capinação e varrição em várias áreas de outros bairros. Entretanto, queixam-se de que estas ações não são realizadas com a freqüência adequada e em alguns locais de mais difícil acesso do bairro. Fazem comparações com a baixa freqüência da coleta no bairro onde residem (classe baixa), com a coleta regular que é realizada em bairros considerados de classe média e alta, sentindo-se prejudicadas. Relatam ainda que durante as eleições os candidatos a governo prometem melhorias, que são esquecidas após o período eleitoral.

Durante as entrevistas observou-se uma diferenciação, ainda que pouco precisa, entre o espaço de domínio público e o de domínio privado. Para as mulheres, o domínio privado corresponde ao que está sob o controle daquela casa, que inclui o domicílio e a área imediatamente ao redor da mesma, incluindo o quintal e espaços laterais e frontais. Este espaço é considerado de responsabilidade daquela família e 
o poder para a solução do problema, naquela área, depende da mesma. Assim, a retirada do lixo jogado nesta área é considerada responsabilidade do proprietário do domicílio e, quando os vizinhos jogam lixo naquele espaço, surgem conflitos de vizinhança.

O que está fora do domicílio e distante dos arredores dele é compreendido como da responsabilidade de "outros", podendo ser outro proprietário ou o poder público. O poder para a solução do problema, para elas, neste caso, não está no âmbito individual. O espaço inabitado parece constituir-se em uma área sem identidade, estando sujeita a ser mais utilizada como pontos de lixo não autorizados.

Os relatos apontam que os moradores das baixadas estão sujeitos aos mais graves problemas relacionados ao lixo e ao somatório de fatores de riscos ambientais que afetam a saúde. Nestas áreas, as pessoas convivem com esgotos, falta de água, acúmulo de lixo e sob o risco permanente de enchentes e desabamentos. As entrevistadas se queixam de que, quando reivindicam o acesso a esses serviços junto aos órgãos públicos, são usualmente mal recebidas e raramente suas solicitações são atendidas. Uma das mulheres colocou seu sentimento de injustiça em morar naquelas condições, mas, ao mesmo tempo, parece conformada diante da situação, concluindo que poderia estar em pior condição.

"A gente mora num lugar assim, porque a gente não tem pra onde ir, porque não temos condições de ter um lugar melhor, [...] aqui pra ter uma morada. Mas eu agradeço a Deus por esse cantinho que muitos têm pior por aí, debaixo de uma ponte, não tem onde passar chuva. $O$ negócio é a gente zelar pelo o que a gente tem. Lá fora tá sujo, tem lixo, mas enquanto nossa casa tiver limpinha, tudo limpinho pronto" (Luci).

\section{Discussão}

Os resultados deste estudo apontam para a definição de lixo como aquilo que não serve para ser utilizado, vendido ou trocado, sendo descartado. Lixo é uma categoria dinâmica, pois o que é lixo para algumas pessoas, pode ser de grande utilidade para outras. Os componentes deste descarte são frutos de decisões individuais, mas que podem ser determinadas histórica, social ou culturalmente.

A valorização e a categorização de um produto como lixo apresenta uma dimensão temporal. Segundo alguns relatos, o lixo recolhido em um dado momento serve para ser vendido, constituindo-se como um meio de sobrevivên- cia, em outros, quando esta atividade econômica deixa de existir, é considerado como um produto descartável.

A identificação do que é considerado lixo envolve processos de escolhas que eventualmente requerem decisões, um objeto ou produto pode ser mantido ou descartado, pode-se optar por reutilizá-lo, guardá-lo para uso posterior, ou doá-lo a alguém. Se a opção é pelo descarte o objeto é então definido como lixo, o destino dele, em geral, é ser removido para lugares fora do domicílio. Como os costumes se alteram ao longo do tempo, a definição e caracterização do que é lixo refletem essas mudanças temporais. Strasser (1999), ao enfocar a categorização do processo que define lixo, relata que a idéia, em geral, se voltará quase sempre para um amontoado de objetos ou produtos descartados e acumulados. No entanto, a reflexão que se faz neste estudo é que o lixo também é percebido como disperso no ambiente.

Quando o lixo é conceituado pelas mulheres como "o que não serve para ser utilizado" e, por isso, aquilo que não pode constituir-se em um produto de reciprocidade, de troca, reflete um processo de escolha e de classificação. É claro que a escolha é limitada pelas condições econômicas, que por sua vez determinam o consumo e o descarte do produto. Assim, aqueles que têm menos para consumir, quase não têm o que descartar e aproveitam ao máximo o que podem adquirir. Para Strasser (1999), os países desenvolvidos, mais comumente que os menos desenvolvidos, descartam coisas simplesmente porque não as querem mais. Segundo Douglas (1966), nada é inerentemente lixo e para algo ser considerado lixo, faz-se necessária uma ordenação sistemática dos produtos e uma classificação contextualizada.

O processo de escolha do que é lixo varia de indivíduo para indivíduo, difere de lugar para lugar e muda com o tempo. As categorias dos objetos descartados são socialmente definidas. Alguns grupos, especialmente os menos favorecidos, reutilizam mais facilmente as coisas que outros, e os processos de doações e de trocas de objetos descartados limitam-se às vezes a concepções ou crenças religiosas. Acima de tudo, a seleção dos produtos a serem considerados como lixo varia com a classe social. O que é lixo para uns é valorizado por outros, e aqueles que mais valorizam pertencem, na grande maioria das vezes, a uma classe social menos favorecida. Quanto às mudanças com o tempo, sabe-se que durante a recessão econômica a produção de lixo em geral diminui, em função da redução do poder aquisitivo da população (Acurio et al., 1997). 
Percebe-se uma dimensão espacial na disposição dos produtos considerados lixo. Estes ocupam lugares marginais dentro de casa, como a cozinha e a área de serviço; ou fora dela, como o quintal ou a calçada. Douglas (1966) chama a atenção para os lugares mais periféricos das casas, designados como pontos de colocação do lixo. Para esta autora o que é descartado ocupa um lugar situado entre as esferas do ambiente público e do privado, na fronteira onde o domínio doméstico encontra-se com o ambiente externo da rua. Verificou-se neste estudo que os lugares próximos aos espaços de disposição do lixo, como quintal e passeio, costumam ser usados por crianças para brincadeiras e jogos, o que as expõem com regularidade ao contato com resíduos contaminados, fontes de agentes patógenos.

Os domicílios e as áreas imediatamente ao redor da casa, pertencentes ao terreno, também fazem parte do domínio privado, sendo utilizados como área de lazer. Esta delimitação entre o privado e o público, além de determinar a responsabilidade sobre a coleta nestes lugares, implica também na identificação dos locais para disposição do lixo. Conforme Cairncross et al. (1996), em muitas culturas, especialmente nos trópicos, os limites do domínio privado são determinados pelos proprietários, que utilizam ordinariamente as áreas externas da casa para trabalhos domésticos, banhos e refeições. Para estes autores a delimitação dos limites entre esses dois domínios determina a prioridade na intervenção, se no âmbito comportamental ou de infra-estrutura e regulação.

As entrevistadas relatam diferenças espaciais no acesso à coleta do lixo na cidade e internamente no bairro, que se relacionam também à situação topográfica do local onde residem. Os entrevistados, moradores de uma típica periferia urbana, relatam deficiências de infra-estrutura, sentindo-se marginalizados quanto ao acesso à coleta do lixo, comparando-a com aquela realizada em bairros de classes média e alta. Os que residem nas baixadas, por sua vez, recebem o lixo de quem mora acima e se queixam da ineficiência dos serviços públicos essenciais como a limpeza pública. Esses achados são reforçados por informações censitárias de 1989, quando o acesso à coleta, no Brasil, era de $51,3 \%$, para a classe de renda até um salário mínimo e de $89,0 \%$, nas classes de renda superior a cinco salários mínimos (MMA, 1999).

Deve-se considerar que uma cidade como Salvador, com peculiaridades topográficas, climatológicas e sócio-econômicas, requer soluções específicas para os graves problemas causados pelo lixo, levando-se em conta que o mes- mo não constitui um problema ambiental isolado, somam-se a ele aqueles decorrentes da ocupação desordenada do solo e da falta de infra-estrutura como drenagem, esgoto e água; problemas que, ao se acumularem no mesmo espaço geográfico, favorecem ou agravam as condições de risco ambiental local.

A identificação do lixo enquanto um problema sentido varia de acordo com o indivíduo em seu contexto histórico, tornando-se adequado o resgate do conceito de problema utilizado por Matus (1993:580) como "a formulação para um ator social de uma discrepância entre a realidade constatada ou simulada e uma norma de referência que ele aceita ou cria". Em outras palavras é a identificação da diferença entre "o que é" e "o que deveria ser", de acordo com padrões e valores considerados desejáveis do ponto de vista do ator social. Para Samaja (2000), o conceito de problema só tem aplicação no sistema vivo e nos processos humanos e são componentes de uma ordem descritiva que serve para qualificar estados possíveis, nos indivíduos vivos em toda a extensão da biosfera. A compreensão do que é "transtorno" ou "problema”, para Samaja, não deriva nem de processos indutivos da simples observação dos fenômenos, nem da criação espontânea da consciência, mas das representações que os membros da comunidade possuem do fenômeno, que são herdados de "modelos que organizam a experiência”. Estes últimos, por sua vez são culturalmente herdados da "sedimentação milenar da história social” (Samaja, 2000:51).

Os relatos detalhados dos processos de adoecimento, por exemplo a transmissão da diarréia e das parasitoses intestinais, a partir do contato das crianças com o lixo, nos remetem à natureza complexa, subjetiva e contextual da relação entre saúde/doença/cuidado e aos processos interativos das relações entre os sujeitos humanos e seu meio ambiente. Podese verificar, nas análises das entrevistas realizadas, que os mecanismos apontados para a transmissão das doenças são coerentes com o que está descrito na literatura. Esta compreensão é certamente resultante de "modelos que organizam a experiência”, apontando para a necessidade de mais estudos para a elucidação da relação entre o lixo, como um fator de risco ambiental, e saúde. Com relação à possível associação entre doença e fatores de risco ambientais, pode-se concordar com as idéias de Almeida Filho (2000) que não se trata apenas de uma ação externa de um elemento ambiental agressivo, nem da reação de um hospedeiro susceptível, senão de um sistema (totalizado, interativo, processual) de efeitos patológicos. 
Parece existir uma compreensão, ainda que superficial, por parte das entrevistadas, de como o lixo provoca degradação e desastres ambientais. As condições de vida desfavoráveis determinam, pelo menos em grande parte, um consumo reduzido, que leva a uma menor produção de resíduos e a reutilização de produtos que seriam descartados. Algumas práticas que surgem de maneira espontânea no bairro como meio de subsistência tornam os moradores dessas áreas mais facilmente predispostos a acolherem programas que utilizam as concepções atuais de gerenciamento dos resíduos sólidos urbanos, os três erres (redução, reutilização e reciclagem) (MMA, 1999). Estas práticas poderiam ser mais valorizadas na elaboração das políticas públicas locais em relação ao lixo.

A identificação dos problemas relacionados ao lixo carece de uma delimitação mais precisa por implicarem em decisões diferenciadas de intervenção. Se o problema identificado encontra-se na esfera do domínio público, as políticas de intervenção devem ser direcionadas principalmente com investimento em infra-estrutura e em regulação pública. Caso o problema situe-se na esfera do domínio privado, as intervenções devem voltar-se principalmente para as ações educativas e de mudanças de hábitos, associadas às melhorias que são de responsabilidade da esfera pública.

O lixo é entendido como um problema quando: encontra-se acumulado no ambiente e é capaz de provocar incômodos como mau cheiro ou poluição visual; serve como foco da presença de animais; provoca doenças em crianças e adultos ou quando o poder para a solução do problema desloca-se da esfera individual para ser uma questão coletiva e/ou institucional. Entende-se que a discussão sobre as possíveis soluções para o problema do lixo requer fóruns mais amplos de debate com a população, que ultrapassem os limites de gabinetes governamentais e se aproximem cada vez mais da realidade local.

Os moradores das áreas periféricas, já destituídos de muitos direitos de cidadania, são os mais prejudicados com a deficiência de coleta pública de lixo. Seguindo a recomendação da Agenda 21, faz-se necessária uma maior discriminação positiva para reduzir a desigualdade no acesso à coleta, além de uma maior regulação e fiscalização das empresas prestadoras deste serviço, por parte do Estado (MMA, 1999).

Dentre os aspectos relevantes levantados neste estudo está o modo como as populações expostas ao contato com o lixo a céu aberto percebem isto enquanto um problema, associando-o à situação de saúde ou a outros problemas ambientais. Neste sentido, este estudo, ao buscar compreender esta problemática em uma perspectiva êmica, procurou trazer contribuições para a compreensão deste complexo tema.

\section{Agradecimentos}

Os autores agradecem à Secretaria de Saneamento e Recursos Hídricos do Estado da Bahia, por intermédio do Projeto de Avaliação do Impacto Epidemiológico do Programa de Saneamento Ambiental da Baía de Todos os Santos - Projeto Bahia Azul; ao Programa de Apoio a Núcleos de Excelência, Ministério da Ciência e Tecnologia (661086/1998-4); à Organização PanAmericana da Saúde, pelo Programa de Subvenções para Teses de Pós-Graduação (AMR00/074302-01); ao Conselho Nacional de Desenvolvimento Científico e Tecnológico (bolsa no140594/2000); a Evandro Calixto Filho e à Anita Gil, pela transcrição das fitas; e a Marco Rêgo, Mônica Nunes, Ana Cerqueira e Iêda Franco, pela leitura crítica das várias versões deste artigo. 


\section{Referências}

ACURIO, G.; ROSSIN, A.; TEIXEIRA, P. F. \& ZEPETA, F., 1997. Diagnóstico de la Situación de Manejo de Residuos Sólidos Municipales en América Latina el Caribe. Washington, DC: Banco Interamericano de Desarrollo/Organización Panamericana de la Salud.

ALMEIDA FILHO, N., 2000. A Ciência da Saúde. São Paulo: Editora Hucitec.

BARRETO, M. L. (org.), 1999. Avaliação do Impacto Epidemiológico do Programa de Saneamento Ambiental da Baía de Todos os Santos (Bahia Azul), 9o Relatório Quadrimestral. Salvador: Secretaria de Recursos Hídricos Saneamento e Habitação/ Instituto de Saúde Coletiva, Universidade Federal da Bahia.

BENTLEY, M.; PELTO, G.; STRAUSS, W.; SCHUMANN, D.; ADEGBOLA, C.; PENA, E.; ONI, G.; BROWN, K. \& HUFFMAN, S., 1988. Rapid ethnographic assessment: Implication in a Diarrhea Management Program. Social Science and Medicine, 27:107-116.

CAIRNCROSS, S.; BLUMENTHAL, U.; KOLSKY, P.; MORAES, L. R. \& TAYEH, A., 1996. The public and domestic domains in the transmission of disease. Tropical Medicine and International Health, 1:2734.

CATAPRETA, C. A. A. \& HELLER, L., 1999. Associação entre coleta de resíduos sólidos domiciliares e saúde, Belo Horizonte (MG), Brasil. Pan American Journal of Public Health, 5:88-96.

DATASUS (Departamento de Informática do SUS), 2000. Cobertura de Sistema de Coleta de Lixo da Região Metropolitana de Salvador, 1997-1999. 9 Novembro 2001 <http://tabnet.datasus.gov.br/ cgi/tabcgi.exe? IDB2000/f19.def $>$.

DOUGLAS, M., 1966. Purity and Danger: An Analysis of Concepts of Pollution and Taboo. London/New York: Routledge/Kegan Paul.

ESREY, S. A.; POTASH, J. B.; ROBERTS, L. \& SHIFF, C., 1991. Effects of improved water supply and sanitation on ascariasis, diarrhoea, dracunculiasis, hookworm infection, schistosomiasis and trachoma. Bulletin of the World Health Organization, 69:609-621.

FILEMAKER INCORPORATION, 1994. FileMaker Pro 4.1 Author Professional Custom Solutions. Project Planning Software <http://www.filemaker.com>.

HELLER, L., 1995. Associação entre Cenários de Saneamento e Diarréia em Betim - MG: O Emprego do Delineamento Epidemiológico Caso-controle na Definição de Prioridades de Intervenção. Tese de Doutorado, Belo Horizonte: Escola de Veterinária, Universidade Federal de Minas Gerais.

HELLER, L., 1997. Saneamento e Saúde. Brasília: Organização Pan-Americana da Saúde/Organização Mundial da Saúde.

HUTTLY, S. R.; LANATA, C. F.; YEAGER, B. A.; FUKUMOTO, M.; DEL AGUILA, R. \& KENDALL, C., 1998. Feces, flies, and fetor: Findings from a Peruvian shantytown. London School of Hygiene and Tropical Medicine, Maternal and Child Epidemiology. Revista Panamericana de Salud Pública, 4:75-79.

IBGE (Fundação Instituto Brasileiro de Geografia e Estatística), 2000. Pesquisa Nacional por Amos- tras de Domicílios 1999. Microdados. 9 Novembro 2001 <http://www.ibge.gov.br/ibge.caovida/indi cadoresminimos/tabela3.shtm $>$.

JENKINS, C. \& HOWARD, P., 1992. The use of ethnography and structured observations in the study of risk factors for transmission of diarrhea in highland Papua New Guinea. Medical Anthropology, 15:1-16.

LARREA, C. \& BARRETO, M. (org.), 1999. Acompanhamento das Mudanças das Percepções da População Resultantes das Ações do Programa Bahia Azul. Relatório Técnico de Pesquisa. Salvador: Secretaria de Recursos Hídricos Saneamento e Habitação/Instituto de Saúde Coletiva, Universidade Federal da Bahia.

LIMPURB (Companhia de Limpeza Urbana), 2000. Relatório Técnico Anual. Salvador: LIMPURB, Prefeitura Municipal de Salvador.

MATUS, C., 1993. Política, Planificação e Governo. Brasília: Instituto de Pesquisa Econômica Aplicada.

MMA (Ministério do Meio Ambiente), 1999. Agenda 21 Brasileira: Bases para a Discussão. Brasília: MMA.

MORAES, L. R. S., 1997. Aspectos epidemiológicos relacionados aos resíduos domiciliares urbanos: Um estudo de caso. In: 19o Congresso Brasileiro de Engenharia Sanitária e Ambiental, Anais, CDROM. Foz do Iguaçu: Associação Brasileira de Engenharia Sanitária e Ambiental.

UN (United Nations), 1999. Environmentally Sound Management of Solid Waste and Sewage-related Issue. 29 May $2000<$ http://www.un.org/esa/ sustdev/agenda21 chapter21.htm>.

OPS (Organización Panamericana de la Salud), 1993. Nuestro Planeta, Nuestra Salud: Informe de la Comisión de Salud y Medio Ambiente de la OMS. Publicación Científica 505. Washington, DC: OPS.

RÊGO, R. C. F., 1996. Destino dos Dejetos, Lixo e Diarréia Infantil em uma Comunidade Periurbana de Salvador, Bahia. Dissertação de Mestrado, Salvador: Instituto de Saúde Coletiva, Universidade Federal da Bahia.

SAMAJA, J., 2000. A Reprodução Social e a Saúde: Elementos Metodológicos sobre a Questão das Relações entre Saúde e Condições de Vida. Salvador: Editora Casa da Qualidade.

SISINNO, C. L. S. \& OLIVEIRA, R. M. (org.), 2000. Resíduos Sólidos, Ambiente e Saúde: Uma Visão Multidisciplinar. Rio de Janeiro: Editora Fiocruz.

STRASSER, S., 1999. Toward a History of trash making. In: Waste and Want: A Social History of Trash (S. Strasser, ed.), pp. 3-19, New York: Metropolitan Books.

Recebido em 6 de fevereiro de 2001

Versão final reapresentada em 22 de fevereiro de 2002 Aprovado em 3 de abril de 2002 